\title{
Molecular Detection of Epstein Barr Virus, Human Papilloma Virus Types 16,18 in Breast Cancer Patients in Khartoum State Sudan
}

ISSN: 2637-773X

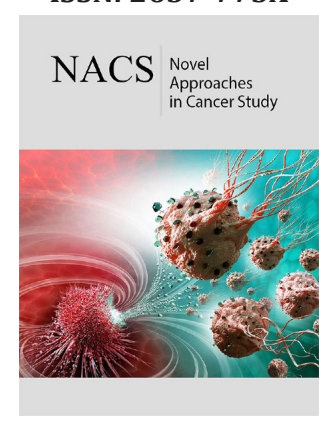

*Corresponding author: Khalid A Enan, Department of Virology Central Laboratory, Ministry of High Education and Scientific Research, Khartoum, Sudan

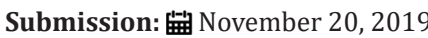

Published: 眥 December 09, 2019

Volume 4 - Issue 1

How to cite this article: Israa M Osman Abdel Rahim M El Hussein, Isam M Elkhidir, Azza Babiker, Khalid A Enan. Molecular Detection of Epstein Barr Virus, Human Papilloma Virus Types 16,18 in Breast Cancer Patients in Khartoum State Sudan. Nov Appro in Can Study. 4(1) NACS.000576.2019.

DOI: $10.31031 /$ NACS.2019.04.000576

Copyright@ Khalid A Enan, This article is distributed under the terms of the Creative Commons Attribution 4.0 International License, which permits unrestricted use and redistribution provided that the original author and source are credited.

\author{
Israa M Osman ${ }^{1}$, Abdel Rahim M El Hussein ${ }^{2}$, Isam M Elkhidir ${ }^{3}$, Azza Babiker ${ }^{2}$ \\ and Khalid A Enan ${ }^{2 *}$ \\ ${ }^{1}$ University of Medical Sciences and Technology, Sudan \\ ${ }^{2}$ Department of Virology Central Laboratory, Sudan \\ ${ }^{3}$ Department of Microbiology and Parasitology, Sudan ${ }^{3}$
}

\begin{abstract}
Background: Breast cancer is the most common among female, constituting about $18 \%$ of all female cancers, with 1.7 million new cases reported in the world each year. Recently some studies reported that approximately $18 \%$ of cancer cases can be linked to infectious agents including viruses particularly Human Papilloma Virus (HPV) and Epstein Barr virus (EBV).
\end{abstract}

Objective: Molecular detection of EBV and HPV types 16 and 18 in breast cancer patients in Khartoum State, Sudan.

Methods: Paraffin embedded blocks of tumor specimen from 70 Sudanese patients with breast cancer were collected from Omdurman teaching Hospital, Sudan, during the period from March to June 2018. PCR was used to investigate the presence of EBV and HPV type 16, 18 viruses in these specimens.

Results: The results show that eight out of 70 patients were positive for EBV virus (11.4\%) Of these positive patients, $3(4.2 \%)$ were $30-50,3(4.2 \%)$ were $51-80$ and $2(2.8 \%)$ were $81-100$ years old, respectively. Seven out of the 70 patients were positive for HPV type 18(10\%). Of these positive patients, $5(7.1 \%)$ were $30-50 y e a r s$ old and $2(2.9 \%)$ were $50-80$ years old. None of the patients were found positive for HPV type 16. No significant differences were found between age groups as regards infection by EBV or HPV type 18 viruses.

Conclusion: The incidence of EBV and HPV types 18 in breast cancer patients in Khartoum State was documented through the molecular detection of these two virus's DNA. Detection of EBV and HPV type18 using PCR was established. Generally, these findings are useful for future studies since there is little information available about of EBV and HPV types 16, 18 in Sudan.

Keywords: EBV and HPV16,18; Breast Cancer; Khartoum State; Sudan

\section{Introduction}

Breast cancer is a type of cancer originating from breast tissue, most commonly from the inner lining of milk ducts or the lobules that supply the ducts with milk [1]. The size, stage, rate of growth, and other characteristics of the tumor determine the kinds of treatment. Treatment may include surgery, drugs (hormonal therapy and chemotherapy), radiation and/ or immunotherapy [2]. Many factors including radiation, chemicals and viruses, have been found to induce human cancer [3]. Viral factors are the most important class of the infectious agents associated with human cancers [4]. It was estimated that $17-20 \%$ of the worldwide incidence of cancers was attributable to a viral etiology [5]. Infections with oncogenic viruses have been investigated as possible risk factors for a breast cancer aetiology including mouse mammary tumor virus (MMTV), Epstein-Barr virus (EBV) and human papilloma virus (HPV) especially types 16,18 , and 33; however, their presice role is not clear. EBV was the first human virus to be directly implicated in carcinogenesis. Epstein Barr virus; a common infection affecting over $90 \%$ of the world's population is one of the viruses that have some unclear and controversial points over its ability to trigger the development of certain tumors [6] such as Burkett's lymphoma, nasopharyngeal carcinoma, Hodgkin's disease, gastric carcinoma and post-transplant lymphoproliferative disease [7]. 
The small untranslated RNAs EBER-1 and -2 are accumulated at high levels during all forms of latency and regulate apoptosis through different mechanisms which play a critical role in efficiency of EBV-induced growth transformation of primary B cells.EBER-1 interacts with the interferon-inducible protein kinase R (PKR), and inhibits its activation by double stranded RNAs, protecting infected cells from IFN-induced apoptosis [8]. However, Wu et al. [9] also reported that EBVencoded RNA 2 (EBER2) but not EBER1 playing a critical role in EBV-induced B-Cell growth transformation. In Sudan, breast cancer is characterized by a geographically focal nature, early onset and aggressive course of the disease [10]. BRCA1, BRCA2 and p53 mutations are infrequent in Sudanese breast cancer patients. Epigenetic changes are suggested as alternative mechanisms to account for the minor contribution in the genetic alterations in three tumor suppressor genes, BRCA1, BRCA2, and p53, in both sporadic and familial breast cancer cases in Sudan [11].

\section{Materials and Methods}

\section{Patient criteria and specimen collection}

Paraffin embedded blocks of tumor specimens from 70 Sudanese patients with breast cancer were collected from Omdurman Teaching Hospital Sudan during the period from March to June 2018. The collected specimens were stored at room temperature until the test was performed.

Specimen deparaffinization: This was carried outas recommended in the protocol using the DNA extraction kit (Acrogene, USA) The specimens were deparaffinized according to the protocol of the manufacturerDNA extraction procedure was carried out according to manufacturer's protocol (Acrogene, USA).

\section{DNA extraction}

The procedure was carried out according to manufacturer's protocol (Acrogene,USA).

Polymerase Chain Reaction (PCR) for detection of EBV: The PCR was performed using primers that are specific for the EBV (gB) conserved regions. The primers used consisted of forward primer SL1, 5-GGACCTCAAAGAAGAGGGGG-3 and the reverse primer SL3, 5-GCTCCTGGTCTTCCGCCTCC-3. The reaction was performed in $25 \mu \mathrm{L}$ volume of PCR PreMix master mix (Intron Biotechnology, Korea). The volume included $5 \mu \mathrm{L}$ master mix, $\mu \mathrm{L}$ forward primer (10pg), $1 \mu \mathrm{L}$ reverse primer (10pg), $5 \mu \mathrm{L}$ extracted DNA and $12 \mu \mathrm{L}$ distilled water. The DNA was amplified in a thermo cycling condition using PCR machine (Techno, Japan) as follow: initial denaturation at $95^{\circ} \mathrm{C}$ for $10 \mathrm{~min}$, followed by 35 cycles of denaturation at $95^{\circ} \mathrm{C}$ for $45 \mathrm{sec}$, annealing at $60^{\circ} \mathrm{C}$ for $45 \mathrm{sec}$ and extension at $72^{\circ} \mathrm{C}$ for $60 \mathrm{sec}$, with final extension at $72^{\circ} \mathrm{C}$ for $10 \mathrm{~min}$. The expected size of UTR gene amplicon was 80bp [12].

Polymerase Chain Reaction (PCR) for detection of HPV types 16 and 18: Samples were amplified separately for HPV 16 and 18 with a thermocycler (Techno, Japan), and primers specific for each viral type derived from previously published sequences $(12,40)$. The sequence of primers for HPV 16 DNA were F, 5'TTTIGGGTTACA CAT'TACAAG3' (residues 7864 to 7885), and R, 5'TGTC TGCTJT'J'7'ATACTAACCG3' (residues 57 to 78), which generated a 119-bp product from the URR region. The sequence of primers for HPV 18 DNA were, , F 5'GACACCTTAATGAAAAACGACGA3' (residues 460 to 482), and R,5'CGTCGTTGGAGTCGTTCCTG3' (residues 543 to 562), which amplified a 103-bp fragment from open reading frame E6. The reaction was performed in $25 \mu \mathrm{L}$ volume of PCR PreMix master mix (Intron Biotechnology, Korea). The volume included $5 \mu \mathrm{L}$ master mix, $1 \mu \mathrm{L}$ forward primer $(10 \mathrm{pg})$, $1 \mu \mathrm{L}$ reverse primer $(10 \mathrm{pg}), 5 \mu \mathrm{L}$ extracted DNA and $12 \mu \mathrm{L}$ distilled water. DNA was amplified as follow: 35 cycles of denaturation at $94^{\circ} \mathrm{C}$ for $45 \mathrm{sec}$, annealing at $54^{\circ} \mathrm{C}$ for HPV 16 or $58^{\circ} \mathrm{C}$ for HPV 18 for $1 \mathrm{~min} 45 \mathrm{sec}$ and extension at $74^{\circ} \mathrm{C}$ for $30 \sec ^{[13}$.

\section{Agarose gel electrophoresis}

$10 \mu \mathrm{L}$ of amplified product was analyzed by gel electrophoresis in $2 \%$ agarose stained with $0.15 \%$ ethidium bromide and visualized by using UV gel documentation system (INGeNiuse Germany).

\section{Statistical analysis}

Collected data were analyzed using statistical package for social science (SPSS version 12.0). A p value of $\leq 0.05$ was considered significant.

\section{Result}

\section{Detection of EBV using PCR in breast cancer patients}

Eight out of 70 patients were positive for EBV virus (11.4\%). Of these positive patients, $3(4.2 \%)$ were $30-50,3(4.2 \%)$ were $51-80$ and 2(2.8\%) were 81-100 years old respectively. Seven out of the 70 patients were positive for HPV type $18(10 \%)$. Of these positive patients, 3(4.2\%) were (30-50), 3(4.2\%) were (51-80) and $2(2.8 \%)$ were (81-100) years old, respectively as shown in (Table 1) but with no significant differences.

\section{Detection of HPV types 16, 18 using PCR in breast cancer patients}

Table 1: Detection of EBV, HPV types 16, 18 in breast cancer patients.

\begin{tabular}{|c|c|c|c|c|}
\hline Age Groups in Year & EBV Positive Results (\%) & HPV Type 16 Positive (\%) & HPV Type 18 Positive (\%) & Total \\
\hline $30-50$ & $3(4.5)$ & $0(0)$ & $5(7.6)$ & $8(53.3)$ \\
\hline $50-80$ & $3(4.5)$ & $0(0)$ & $0(3.0)$ & $5(33.3)$ \\
\hline $81-100$ & $2(3.0)$ & $0(0)$ & $7(10.6)$ & $2(13.3)$ \\
\hline Total & $8(12.1)$ & $0(0)$ & 0.814 & $15(100)$ \\
\hline P- value & $0.008^{*}$ & - & \\
\hline
\end{tabular}

*means significant difference

Note: No of patients in age group $30-50$ is 43 , in age group $50-80$ is 20 and in $81-100$ is 3 . 
Seven out of 70 patients were positive for HPV type 18(10\%). Of these positive patients, 5 (7.1\%) were 30-50 years old and 2 (2.9\%) were $50-80$ years old) as shown in (Table 1 ). All the samples were negative for HPV type 16.

\section{Discussion}

Breast cancer is the most common malignancy among females and comprises about $18 \%$ of all cancers affecting them. About 1.7 million new cases are reported in the world each year. Based on the most global recent data, approximately $12.3 \%$ of women are diagnosed with breast cancer at a point of time during their life. Little is known about the viral causes of breast cancer and their epidemiology in Africa. Even much less is known about the epidemiology of viruses associated with breast cancer in Sudan in particular and in Africa in general. Our current study in Sudan is one of the few studies to report directly measured rates of EBV and HPV types 16, 18 associated with breast cancer patients in Sudan. Some studies have reported on the findings that EBV, HPV types 16, 18 play a role in the development of breast cancer including studies from Sudan [14-18], where this were reported in Sudan [16,19]. On the other hand, several studies failed to detect HPV positivity in breast carcinoma [20] even by studying HPV subtypes $6 \mathrm{~b}, 11,13$, $16,18,30,31,32,33,45$, and 51 in 95 women with breast cancer without detecting any of the subtypes [21] researched the HPV subtypes $6,11,16$, and 18 in 13 IDC, 15 papillomas, and 15 papillary carcinomas cases, and there was no evidence of HPV infection [22] did a similar study by using six different primers, including a total of 40 subtypes 16, 18, 31, 33, and 45 in 81 Swiss women cases with breast cancer with no positivity of HPV detected [17].

When studying the prevalence of subtypes of high $(16,18$, 33 , and 45$)$ and low risks $(6,11)$ in 50 breast cancers in women in France by PCR with the general primer GP5+/GP6+, where none of these subtypes were detected in both cases [23]. This may be due to the lack of standardized technique to detect the presence of HPV, since there are different types of primers for different HPV subtypes. False negatives and false positives may occur when PCR overestimates the association between HPV and breast cancer because it cannot indicate which types of cells the virus has infected. Contamination while handling the sample may be partially responsible for the high frequencies of HPV positivity that were reported in several papers. Other risk factors might affect the outcome of the results. For example, studies have shown that women under the age of 25 have a higher prevalence of HPV positivity detection with linear decreasing rate as age increases [24]. Storage of specimens may affect the results, since some researchers found that positive specimens became negative after being frozen for 3 months [25]. Demographic features and genetic backgrounds may also contribute to the geographic difference and HPV infection in breast cancer. The present study focused on the molecular detection of EBV and high-risk HPV types 16 and 18 in breast cancer patients in the Khartoum State. Elnoubi [19] was the first to detect HPV type 16,18 in breast cancer patients in Sudan. The author detected HPV genotype 16, in 21(31\%), and HPV genotype 18, in 10(15\%) of the tested patients. On the other hand, Adam detected EBV genome in 49 (53.3\%) and 10 (11\%) patients by LMP-1 and EBNA-4 PCR, respectively. Based on the results of the present study, findings of Elnoubi [19] and Adam AA [16] that suggest that, EBV, HPV type 18 infection may be common in Sudan. The present study in addition to the above-mentioned studies could serve as a baseline for future plans aiming at introducing the vaccine against EBV and HPV in the Sudan. Finally; these findings should highlight the need for the establishment in Sudan of rapid, sensitive, and specific diagnostic techniques (such as ones used here) to better understand the role played by various viruses in the aetiology of breast cancer development in Sudan.

\section{References}

1. Florescu A, Amir E, Bouganim N, Clemons M (2011) Immune therapy for breast cancer in 2010-hype or hope. Current Oncology 18(1): e9-e18.

2. De villiers EM (2003) Relationship between steroid hormone contraceptives and HPV, cervical interepithelial neoplasia and cervical carcinoma. Int J Cancer 103(6): 705-708.

3. Mao C, Hughes JP, Kiviat N, Kuypers J, Lee SK, et al. (2003) Clinical findings among young women with genital human papillomavirus infection. Am J Obstet Gynecol 188(3): 677-684.

4. Clifford GM, Smith S, Aguado T, Franceschi S (2003) Comparison of HPV type distribution in high-grade cervical lesions and cervical cancer: A meta-analysis. Br J Cancer 89(1): 101-105.

5. Vokes EE, Liebowitz DN, Weichselbaum RR (1997) Nasopharyngeal carcinoma. Lancet 350(9084): 1087-1091.

6. Thornhill Cher (2008) Epstein Barr virus implicated in bladder cancer progression. Int J Urol 15(5): 429-434.

7. Nanbo A, Inoue K, Adachi-Takasawa K, Takada K (2002) Epstein-Barr virus RNA confers resistance to interferon alpha- induced apoptosis in Burkitt's lymphoma. Embo J 21(5): 954-965.

8. Abe T, Nobuo S, Mitsuhiro T, Toru H, Ataru S, et al. (2008) Infiltration of Epstein Barr virus harboring lymphocytes occur in a large subset of bladder cancers. Int J Urol 15(5): 429-434.

9. Wu Y, Maruo S, Yajima M, Kanda T, Takada K (2007) Epstein-Barr Virus (EBV)-Encoded RNA 2 (EBER2) but not EBER1 plays a critical role in EBV-induced B-cell growth transformation. Journal of Virology 81(20): 11236-11245.

10. Masri MA, Abdel Seed NM, Fahal AH, Romano M, Baralle F, et al. (2002) Minor role for BRCA2 (exon11) and p53 (Exon 5-9) among Sudanese breast cancer patients. Breast Cancer Research and Breast Cancer Res Treat 71(2): 145-147.

11. Burchill SA, Bradbury MF, Pittman K, Southgate J, Smith B, et al. (2005) Detection of epithelial cancer cells in peripheral blood by reverse transcriptase-polymerase chain reaction. Br J Cancer 71(2): 278-281.

12. Margall N, Matias-Guiu X, Chillon M, Coll P, Alejo M, et al. (1993) Detection of human papillomavirus 16 and 18 DNA in epithelial lesions of the lower genital tract by in situ hybridization and polymerase chain reaction: cervical scrapes are not substitutes for biopsies. J Clin Microbiol 31(4): 924-930.

13. Shunji M, Hiromi S, Yuji T, Hoichi K, Hiroshi W, et al. (1997) Absence of human papillomavirus-16 and -18 DNA and Epstein-Barr virus DNA in esophageal squamous cell carcinoma. Jpn J Clin Oncol 27(1): 1-5.

14. Bensaber HS, Bicout DJ, Medjamia M, Bensnouci AM, Comez A, et al. (2017) Molecular detection of Epstein Barr virus in women with breast cancer in the west Algeria. Journal of Cancer Therapy 8(3): 16. 
15. Fessahaye G, Elhassan AM, Elamin EM, Adam AAM, Ghebremedhin A, et al. (2017) Association of Epstein - Barr virus and breast cancer in Eritrea. Infectious Agents and Cancer 12: 62.

16. Yahia ZA, Adam AA, Elgizouli M, Hussein A, Masri MA, et al. (2014) Epstein Barr virus: A prime candidate of breast cancer aetiology in Sudanese patients. Infectious Agents and Cancer 9(1): 9.

17. Delgado-García S, Martínez-Escoriza JC, Alba A, Martín-Bayón TA Ballester-Galiana H, et al. (2017) Presence of human papillomavirus DNA in breast cancer: A Spanish case-control study. BMC Cancer17(1): 320.

18. Choi J, Kim C, Lee HS, Choi YJ, Kim HY, et al. (2016) Detection of human papillomavirus in Korean breast cancer patients by real-time polymerase chain reaction and meta-analysis of human papillomavirus and breast cancer. Journal of Pathology and Translational Medicine 50(6): 442-450.

19. Elnoubi, Osman Abdalla Eltayeb (2016) Molecular diagnosis of HPV Isolated from breast cancer patients in Radiation and Isotopes Center Khartoum (RICK), PhD thesis 2016 University of Shandi, Sudan.
20. Wrede D, Luqmani YA, Coombes RC, Vousden KH (1992) Absence of HPV 16 and 18 DNA in breast cancer. British Journal of Cancer 65(6): 891894.

21. Bratthauer GL, Tavassoli FA, O’Leary TJ (1992) Etiology of breast carcinoma: no apparent role for papillomavirus types 6/11/16/18. Pathology Research and Practice 188(3): 384-386.

22. Lindel K, Forster A, Altermatt HJ, Greiner R, Gruber G (2007) Breast cancer and human papillomavirus (HPV) infection: No evidence of a viral etiology in a group of Swiss women. Breast 16(2): 172-177.

23. De Cremoux P, Thioux M, Lebigot, Sigal-Zafrani B, Salmon R, et al. (2008) No evidence of Human papillomavirus DNA sequences in invasive breast carcinoma. Breast Cancer Res Treat 109(1): 55-58.

24. Chang P, Wang T, Yao Q, Lv Y, Zhang J, et al. (2012) Absence of human papillomavirus in patients with breast cancer in north-west China. Medical Oncology 29(2): 521-525.

For possible submissions Click below: 